\title{
Assessment of Gestational Age by Neurological Examination
}

\author{
R. J. ROBINSON \\ From the Nuffield Neonatal Research Unit, Institute of Child Health, Hammersmith Hospital, London W.12
}

In recent years there has been rapidly increasing interest in babies whose birthweight is low because their intrauterine growth has been retarded, and it has been recognized that the clinical problems of these 'small-for-dates' babies differ from those of true prematures. They rarely die from respiratory distress syndrome or intraventricular haemorrhage, but are particularly susceptible to symptomatic hypoglycaemia and intrapulmonary haemorrhage (Gruenwald, 1963; Dawkins, 1965). It is, therefore, a matter of practical importance to know whether a particular baby of low birthweight is truly premature or small-for-dates, a distinction that depends on accurate knowledge of the gestational age. This is most accurately measured by calculation from the first day of the mother's last menstrual period, provided her cycle is regular and her memory correct. Often, however, these conditions do not hold, and some independent method of assessing gestational age is required. Small-for-dates babies cannot be recognized from their general appearance which is often indistinguishable from that of true prematures (Gruenwald, 1963). Most bodily dimensions are affected by the intrauterine growth retardation. Head circumference is a possible exception, but its normal variation is such that it does not by itself give a sufficiently accurate estimate of gestational age. Epiphysial development is a poor index of maturity since it is retarded in smallfor-dates babies (Scott and Usher, 1964; Wigglesworth, 1966).

It has been suggested that the best criteria of maturity are based on neurological development (Gesell and Amatruda, 1945) which is unaffected by intrauterine growth retardation (Bergström, Gunther, Olow, and Söderling, 1955; Saint-Anne Dargassies, 1955; Illingworth and Holt, 1963). However, the methods so far proposed for 'dating' babies by neurological examination have been insufficiently precise, or required too much experi-

Received February 10, 1966. ence in assessment of muscle tone, to be practicable for general use. The present paper reports a study of the presence and absence of a number of reflexes in relation to gestational age. Certain of them were found to have sufficiently predictable times of appearance to provide simple and reliable indices of gestational age.

\section{Clinical Material and Methods}

Eighty-five babies were studied in the Neonatal Ward at Hammersmith Hospital. Since the aim was to analyse the behaviour of normal babies of known gestational age, 23 were omitted from the analysis because either their gestational age calculated from the menstrual dates was uncertain or they had neurological abnormalities. Of the remainder, 37 (19 male, 18 female) were classified as 'normal weight' and 25 (13 male, 12 female) as 'small-for-dates'. 7 of the normal weight group and 6 of the small-for-dates group were of mainly West Indian or African parentage. The birthweights and gestational ages of both series are plotted in Fig. 1.

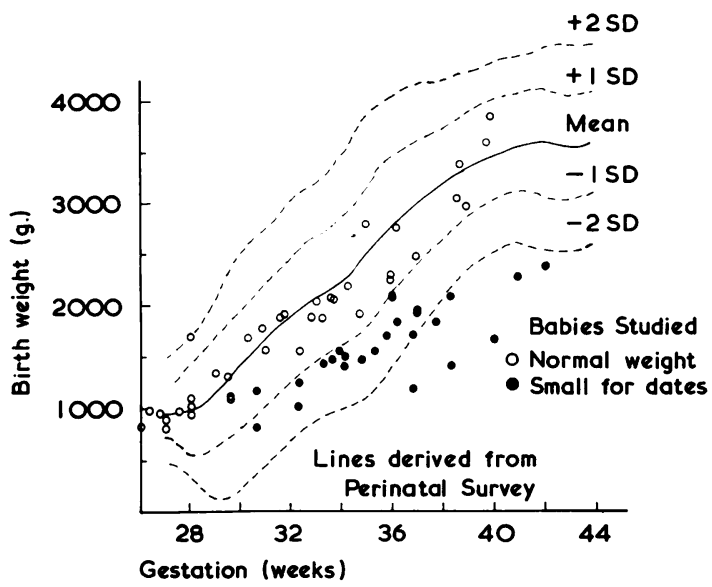

FIG. 1.-Birthweights and gestational ages of the normal weight and small-for-dates babies studied. The lines for mean and standard deviations are derived from the data of the Perinatal Mortality Survey (Butler and Bonham,1963). 
Definitions. The lines for mean birthweight and standard deviations shown in Fig. 1 were derived from the data of the Perinatal Mortality Survey (Butler and Bonham, 1963) by the late Dr. Michael Dawkins. He pointed out that the standard deviations were excessively high at the low gestational ages, because there were very few babies and some had obviously incorrect gestational ages. Consequently if 'more than two standard deviations below the mean birth-weight' is taken as the definition of small-for-dates, it is a far more stringent requirement for babies below 36 weeks than above, and many infants who present the clinical and post-mortem picture of 'smallfor-dates' are excluded. Small-for-dates has therefore been arbitrarily defined as 'more than $25 \%$ below the mean birthweight for the gestational age'. Above 36 weeks' gestation this corresponds to more than 2 standard deviations below the mean. The normal weight group were all less than $20 \%$ below the mean birthweight.

Methods of examination. A standard neurological examination was devised in which the following 20 reflexes and responses were tested: blink response to glabellar tap, palmar and plantar grasp, traction response, plantar reflex, withdrawal on stimulation of foot, crossed extensor reflex, abdominal and cremasteric reflexes, tendon jerks (biceps, knee, and ankle), asymmetrical tonic neck reflexes, neck-righting reflex, Moro reflex, Galant reflex, head-turning towards diffuse light, blink response to light, and pupil size and reactions to light. (The meanings of these terms are explained where necessary in the results section.) The responses were tested as described by Prechtl and Beintema (1964) with slight modifications to reduce the amount of handling of the very small babies. The responses were recorded as present, doubtful, or absent on each side of the body where appropriate. With the more complicated responses each part was recorded separately. For each recording of a response, the 'state of arousal' of the baby at the time was recorded following the system of Prechtl and Beintema. Where there is a 'required state' for a reflex to be elicited, babies were only tested in this state.

Times and numbers of examinations. Examinations were carried out $1 \frac{1}{2}-2$ hours after feeds if possible. Where possible, serial examinations were done once or twice a week in order to obtain a longitudinal study of a particular baby. All examinations were made by the author; a total of 219 was performed (normal weight group, 125; small-for-dates, 94).

\section{Results}

The responses studied fell into 4 main groups. (1) Responses constantly or almost constantly present whatever the state or gestational age of the baby. (2) Responses whose presence or absence depended mainly on gestational age. (3) Responses that were very dependent on the state of arousal. (4) Responses that were variable from baby to baby and from time to time from undetermined causes. For the present purposes the second group are of most interest and the other groups will only be briefly reported in passing.

Responses constantly or almost constantly present. The palmar and plantar grasp responses were present in all the observations on all the babies, though in babies of less than 30 weeks' gestation the palmar grasp consisted of flexion of the fingers only. The withdrawal response on stimulation of the sole of the foot was present in $98 \%$ of all the examinations. The abduction and extension phase of the Moro reflex was present in $99 \%$ of examinations, though in babies less than 28-29 weeks' gestation the response was feeble and of low amplitude. The Galant response (lateral incurvation of the trunk on stimulation of the lumbar skin) was present in $87 \%$ of examinations and the blink response to light in $82 \%$. All these responses were obtained even in babies of 26 weeks' gestation. The slight variability of the last 2 seemed partly dependent on the state of arousal and partly on undiscovered causes. The presence of the abdominal reflexes was very dependent on state of arousal, but provided the baby was not moving or crying they were present in $95 \%$ of observations, including those on the most immature babies.

Responses dependent on gestational age. The presence of 10 responses was found to show a positive correlation with gestational age. 5 of these (pupil reactions, glabellar tap, traction and neckrighting reflexes, and head-turning to light) appeared at definite times in the gestational period, which were the same in the normal weight and the small-for-dates groups. The other 5 responses (crossed extensor, adduction phase of Moro, asymmetric tonic neck and cremasteric reflexes, and knee-jerks) behaved less predictably and the correlation with gestational age was a looser one.

Methods of analysis and presentation of data. Certain methods are used in the analysis of results for each of the responses, and these will be explained first.

(1) Gestation from 25 weeks onwards is divided into 3 (or occasionally 4) periods-the first being the period when the response is usually absent, the second an intermediate period, and the third a period when the response is usually present. For each period the number of occasions on which the response was found present or absent respectively is counted from all the examinations on all the babies falling in that gestational period (whether they were born in it or attained it after birth). The results are recorded as bar diagrams, the number of babies $(\mathbf{N})$ 


\section{Assessment of Gestational Age by Neurological Examination}

on whom the observations were made being recorded under the bars. Results from the normal weight and small-for-dates groups are recorded separately and compared. This method has the advantage that it combines the 'longitudinal' studies of individual babies with the 'transverse' study of all the babies. It is open to the theoretical objection that since unequal numbers of examinations are made on different babies the results may be unduly weighted by many observations on a single baby. For the same reason it is not possible to apply standard statistical tests. Two further methods are used to overcome this difficulty.

(2) The same gestational periods are taken, but only the first examination per baby, made in the first week of life, is counted. The $\chi^{2}$ test can then be applied to test the significance of the differences noticed by inspection of the results.

(3) The third method tests the hypothesis that small-for-dates babies behave like normal weight babies of the same gestational age, and not of the same birthweight. A group of normal weight babies below a certain gestational age is matched for birthweight with a group of small-for-dates babies above that gestational age. The $\chi^{2}$ test (with Yates' correction) applied to the 2 groups indicates whether there is a significant difference in behaviour between babies of the same birthweight depending on gestational age.

Pupil reaction to light. The pupils of premature babies are much more difficult to observe than those of children or adults, partly because the iris is lustreless, and therefore difficult to distinguish from the pupil, and partly because it is difficult to open the eyes and keep them open. (For this reason there is virtually no reliable published information on pupil reactions in premature infants.) Various magnifying devices were experimented with but found to be unhelpful. The method finally chosen was to observe the pupils with the naked eye after gently opening the lids and holding them open with a finger and thumb. An ordinary pen torch, giving a standard light checked by a photographic exposure meter, was used. The pupil size was observed at the moment of switching the light on (it is difficult to see before this), and any subsequent contraction of the pupil noted.

The pupil reaction showed the clearest relationship to gestational age. Fig. 2 shows the results of all the examinations. Pupil reactions were almost invariably absent before 29 weeks' gestation* and present from 31 weeks' gestation. In each of 4

* Throughout this paper (e.g.) 29 weeks means 203 days from the first day of the last menstrual period, mutatis mutandis.

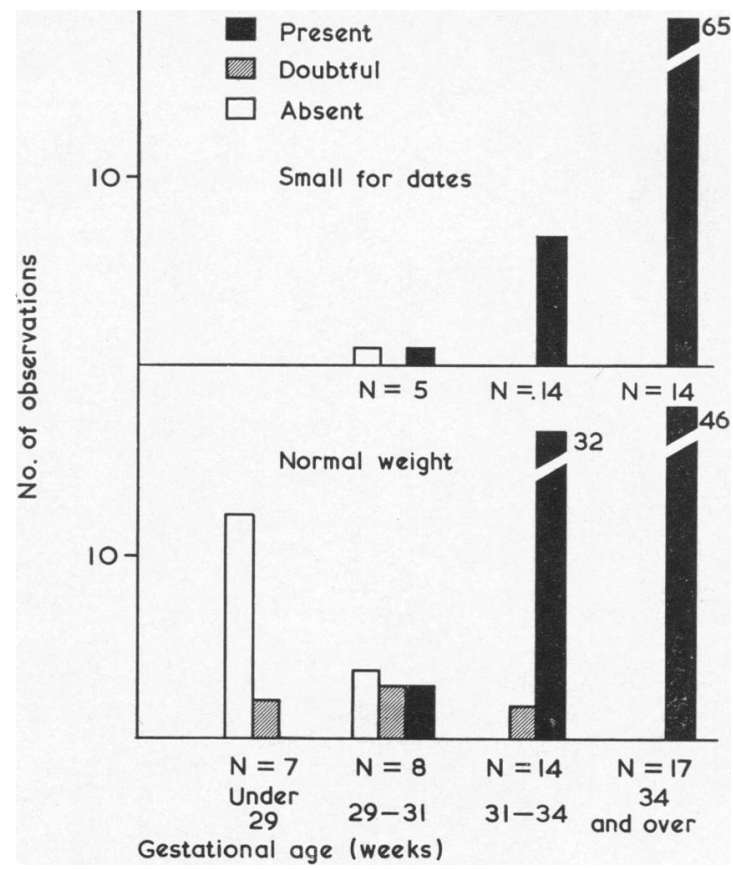

FIG. 2.-Pupil reaction to light. Numbers of observations on small-for-dates and normal weight babies in each gestational period, showing pupil reactions present, doubtful, or absent. $N$ is the number of babies studied in the particular group and period.

babies born before 29 weeks' gestation and examined serially the pupil reactions first appeared between 30 and 31 weeks' gestation, having previously been absent. Table I, giving the results of the first observation on each normal weight baby made in the first week of life, indicates a highly significant difference between the gestational periods ( $p \ll$ 0.001 ).

There were necessarily very few observations on small-for-dates babies under 31 weeks' gestation, but those of 31 weeks and over all behaved like the normal weight babies in showing positive pupil

TABLE I

Pupil Reactions in First Week

\begin{tabular}{|c|c|c|c|c|}
\hline \multirow{2}{*}{ Gestation } & & & \multicolumn{2}{|c|}{$\begin{array}{l}\text { No. of Babies Showing } \\
\text { Pupil Reaction }\end{array}$} \\
\hline & & & Present & $\begin{array}{l}\text { Doubtful or } \\
\text { Absent }\end{array}$ \\
\hline $\begin{array}{l}\text { Under } 31 \text { weeks . } \\
31 \text { weeks and over }\end{array}$ & 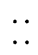 & & $\begin{array}{r}2 \\
43\end{array}$ & $\begin{array}{r}14 \\
0\end{array}$ \\
\hline
\end{tabular}

$\chi^{2}=45$ (Yates' correction), $\mathrm{p} \ll 0.001$. 


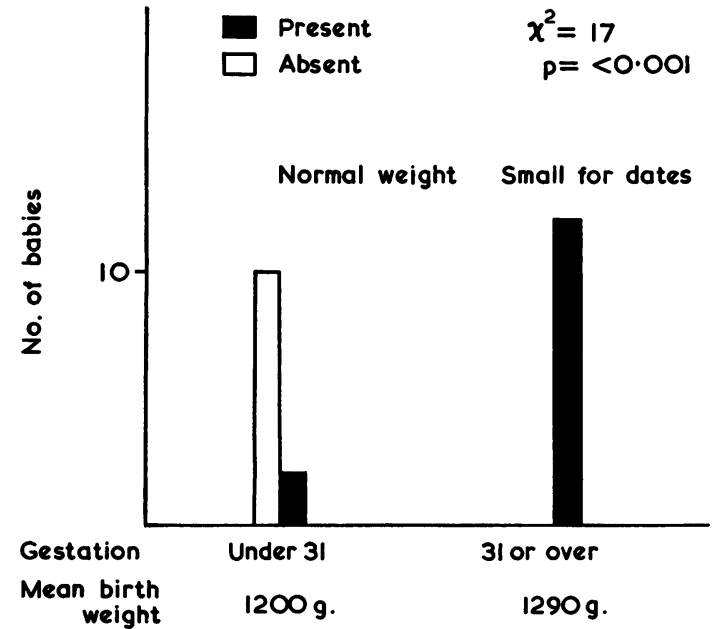

FIG. 3.-Pupil reaction to light in two groups of babies of similar birthweight but different gestational ages. Pupil reactions distinguish between babies under and over 31 weeks' gestation, irrespective of birthweight.

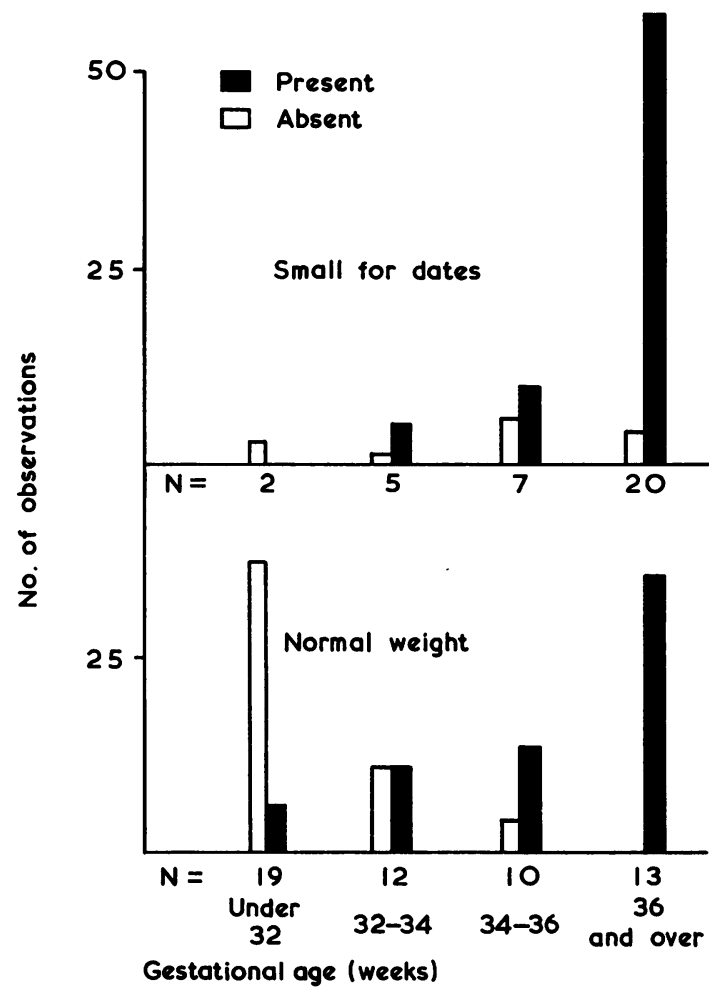

Fig. 4.-Glabellar tap reflex. Numbers of observations on small-for-dates and normal weight babies in each gestational period showing the reflex present or absent. $N$ is the number of babies studied in the particular group and period. responses. Fig. 3 shows that the presence or absence of pupil responses distinguishes significantly $(p<0.001)$ between normal weight babies under 31 weeks' gestation and small-for-dates babies of 31 weeks and over, all the babies being under $1,600 \mathrm{~g}$. and the 2 groups matched for birthweight. The results are again those of the first observation in the first week.

In some very immature babies, usually under 28 weeks' gestation, the eyelids were fused and the pupil responses could not be tested. The responses discussed are the direct reactions to light, but babies who had these present also showed a consensual reaction.

Glabellar tap reflex. This is a blink of the eyelids in response to a tap by a finger on the glabella. A grimace of the whole face, sometimes seen in very immature babies, was not considered a positive response. Fig. 4, based on all the examinations, suggests that the response usually appears

TABLE II

Glabellar Tap Reflex in First Week

\begin{tabular}{|c|c|c|c|c|c|}
\hline \multirow{2}{*}{\multicolumn{4}{|c|}{ Gestation }} & \multicolumn{2}{|c|}{$\begin{array}{l}\text { No. of Babies Showing } \\
\text { Glabellar Tap Reflex }\end{array}$} \\
\hline & & & & Present & $\begin{array}{l}\text { Doubtful or } \\
\text { Absent }\end{array}$ \\
\hline $\begin{array}{l}\text { Under } 32 \text { weeks } \\
\text { Over } 32 \text { weeks }\end{array}$ & $\ddot{x}$ & $\cdots$ & $\dot{*}$ & $\begin{array}{r}4 \\
28\end{array}$ & $\begin{array}{r}17 \\
8\end{array}$ \\
\hline
\end{tabular}

$\chi^{2}=17 \cdot 2$ (Yates' correction), $\mathrm{p}<0.001$.

between 32 and 34 weeks' gestation, both in normal weight and small-for-dates babies. Serial examinations on 5 babies in whom the reflex was initially absent showed that it first appeared between 32 and 34 weeks' gestation. The fourfold table for a single observation in the first week on each baby (Table II) shows that the differences between the gestational periods are highly significant $(p<0.001)$.

Immature and small-for-dates babies of similar birthweight under 2,000 g. are compared in Fig. 5 . The distinction between babies less than 32 and more than 34 weeks' gestation is significant $(p<0.05)$ but at a much lower level than for the pupil reactions.

Traction response. A term baby pulled up by the wrists from the prone position responds by flexing its elbows and bracing the shoulders, and by flexing its neck thus raising the head. The arm flexion and head-raising parts of this response were recorded separately. Both parts tended to appear 


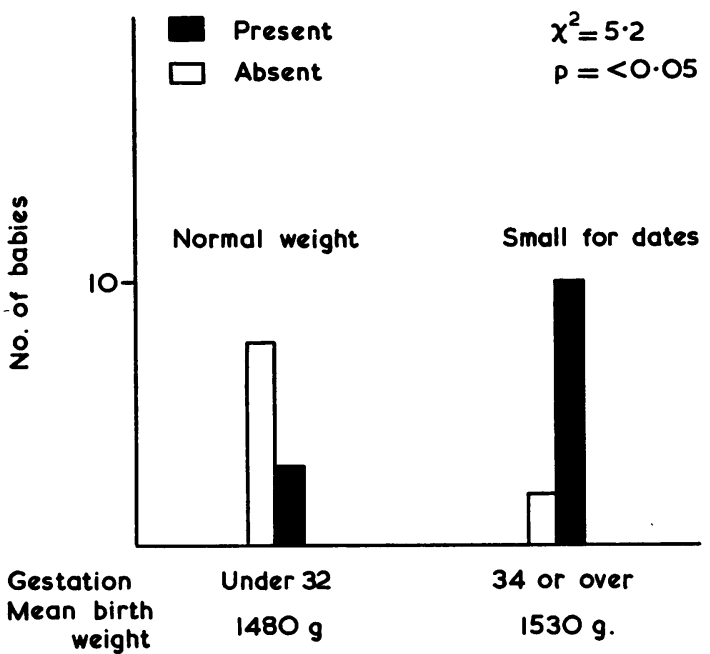

Fig. 5.-Glabellar tap reflex in two groups of babies of similar birthweight but different gestational ages. The reflex distinguishes between babies under 32 and over 34 weeks' gestation, irrespective of birthweight.

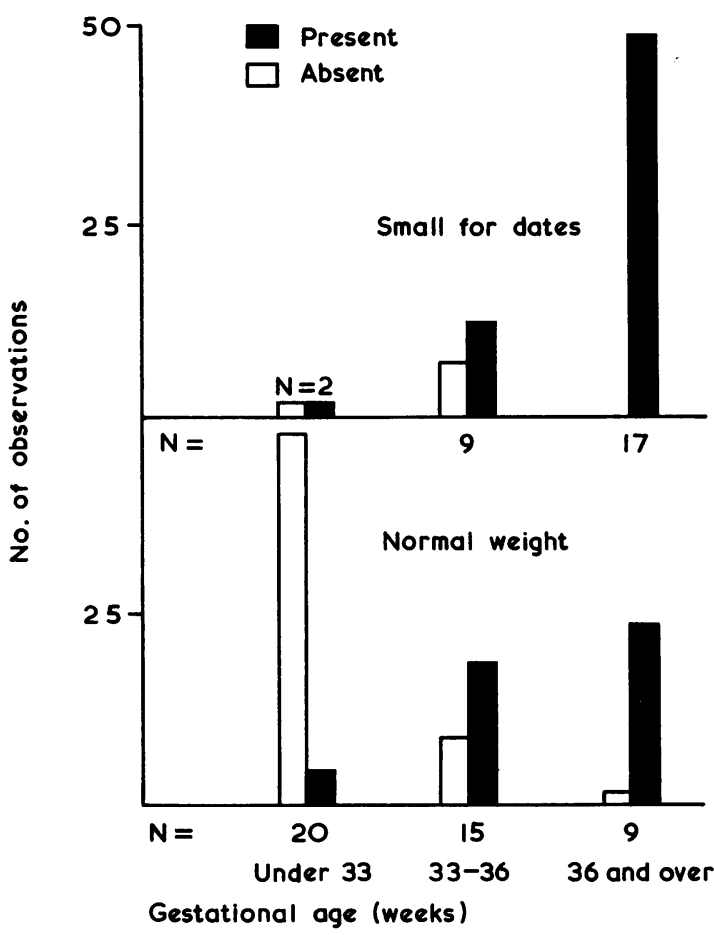

FIG. 6.-Traction response. Numbers of observations on small-for-dates and normal weight babies in each gestational period showing response present or absent. $N$ is the number of babies studied in the particular group and period.

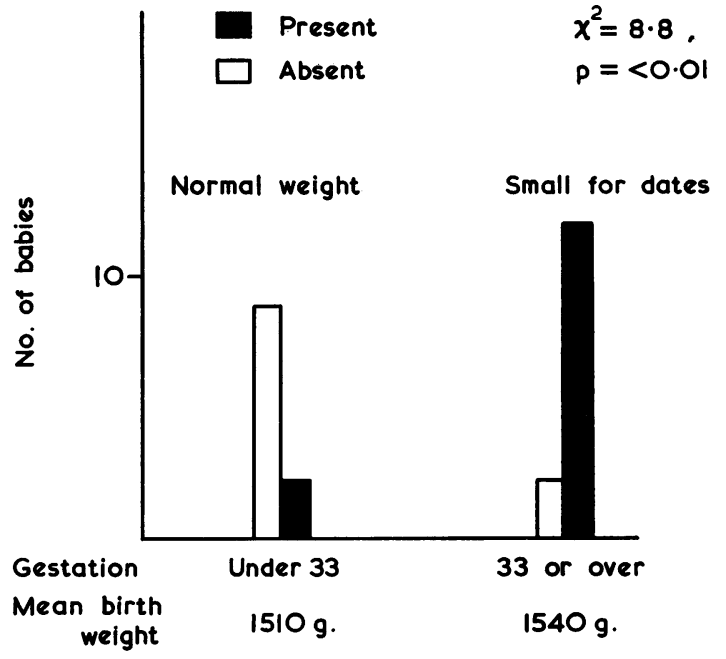

FIG. 7.-Traction response in babies of similar birthweight but different gestational ages. The reflex distinguishes between babies under and over 33 weeks' gestation, irrespective of birthweight.

between 33 and 36 weeks' gestation, but the headraising part generally appeared slightly earlier and behaved more consistently than arm flexion. The response was regarded as positive if either part was present. Fig. 6 shows the results of all the examinations comparing normal weight and small-for-dates babies, who behave very similarly after 33 weeks' gestation.

Table III gives the results of one observation per baby in the first week of life. The differences between the 3 gestational periods are highly significant $(p<0.001)$. Fig. 7 compares immature babies under 33 weeks' gestation with small-fordates babies over 33 weeks of similar birthweight. The distinction between the 2 groups of babies by the traction response is significant $(p<0.01)$.

\section{TABLE III}

Traction Response in First Week

\begin{tabular}{c|c|c|c|c}
\hline Group & Gestation & Present & Doubtful & Absent \\
\cline { 1 - 5 } Normal weight & $\begin{array}{l}\text { Under 33 weeks } \\
\text { 33-36 weeks } \\
\text { 36 weeks and } \\
\text { over }\end{array}$ & 2 & 3 & 15 \\
0 & 3 & 0 & 0 \\
\hline Small-for-dates & $\begin{array}{l}\text { Under 33 weeks } \\
\text { 33-36 weeks } \\
\text { 36 weeks and } \\
\text { over }\end{array}$ & 1 & 0 & 1 \\
\hline
\end{tabular}




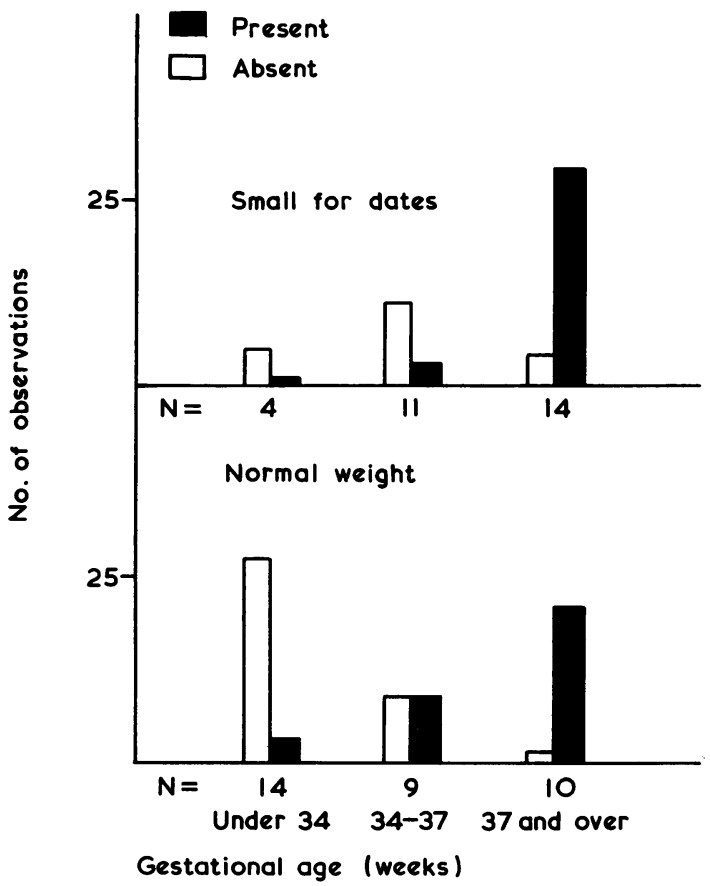

FIG. 8.-Neck-righting reflex. Numbers of observations on small-for-dates and normal weight babies in each gestational period showing response present or absent. $N$ is the number of babies studied in the particular group and period.

Neck-righting reflex. If the head of a term baby is rotated to one or other side, the baby will rotate its trunk in the same direction. Fig. 8 shows that this reflex usually appears between 34 and 37 weeks, both in normal weight and small-for-dates babies. In each of 7 babies followed longitudinally the response appeared at 36-37 weeks having previously been absent. The fourfold table for a single observation on each baby in the first week (Table IV)

TABLE IV

Neck-righting Reflex in First Week

\begin{tabular}{lll|c|c}
\hline \multicolumn{2}{c|}{ Gestation } & & Present & Absent \\
\hline Less than 37 weeks & $\ldots$ & $\ldots$ & 4 & 28 \\
More than 37 weeks & $\cdots$ & $\ldots$ & 6 & 3 \\
\hline
\end{tabular}

$\chi^{2}($ Yates' correction $)=8.4, p<0.01$.

indicates a significant difference between the gestational periods $(\mathrm{p}<0.01)$.

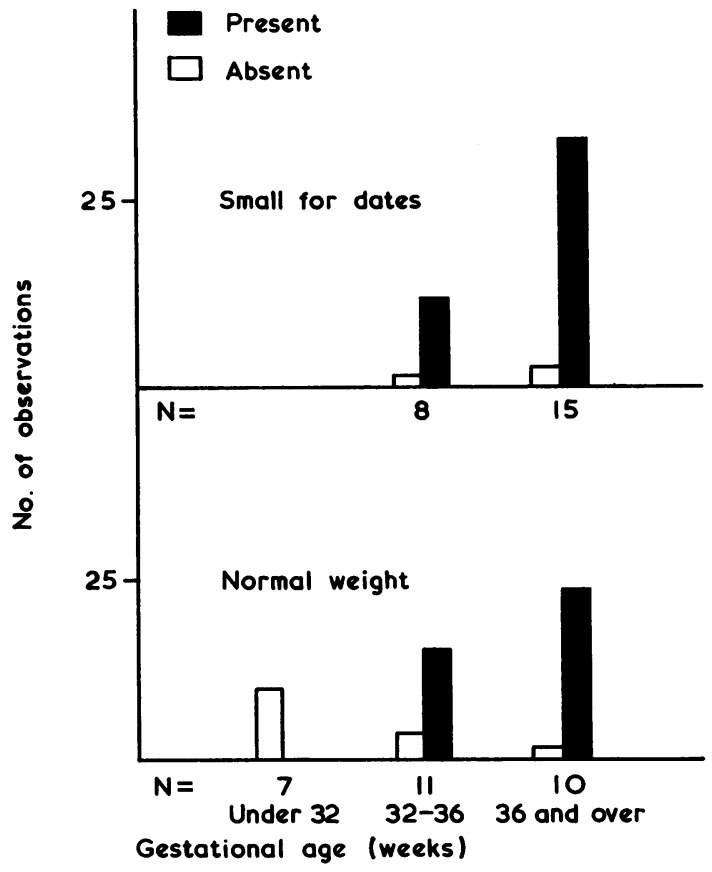

FIG. 9.-Response of turning head towards diffuse light in babies awake but not crying. Numbers of observations on small-for-dates and normal weight babies in each gestational period showing response present or absent. $N$ is the number of babies studied in the particular group and period.

Head-turning to light. If a term baby in a state of quiet alertness is held so that diffuse light falls on one side of its face only, it will slowly turn its head and eyes towards the light. There are practical difficulties in performing this test. The baby must be quietly awake with its eyes open or the result is always negative. It is also very difficult to carry out with the baby in an incubator, so it is rarely possible to test the response in very immature babies who cannot safely be removed. Consequently the numbers of observations are limited especially at the low gestational ages. Fig. 9, in which all the observations on all the babies are plotted, suggests that the response usually appears between 32 and 36 weeks in normal weight babies, and probably in small-for-dates babies also. In 4 babies born at less than 32 weeks' gestation and followed longitudinally, in whom the response was initially absent, the times of first detection were 32, 33, 34, and 36 weeks. The fourfold table for a single observation on each baby in the first week (Table V) shows that the differences between gestational periods are significant $(\mathrm{p}<0 \cdot 01)$. 
TABLE V

Head-turning to Light in First Week

\begin{tabular}{|c|c|c|c|}
\hline \multirow{2}{*}{\multicolumn{2}{|c|}{ Gestation }} & \multicolumn{2}{|c|}{ Head-turning to Light } \\
\hline & & Present & Absent \\
\hline $\begin{array}{l}\text { Less than } 32 \text { weeks } \\
\text { More than } 32 \text { weeks }\end{array}$ & $\begin{array}{ll}\cdots & \cdots \\
\cdots & \cdots\end{array}$ & $\begin{array}{r}0 \\
18\end{array}$ & $\begin{array}{l}6 \\
6\end{array}$ \\
\hline
\end{tabular}

$\chi^{2}=8 \cdot 3$ (Yates' correction), $\mathrm{p}<0.01$.

Crossed extensor reflex. This reflex is elicited by passively extending one leg and stimulating the sole of the foot. A positive response is extension of the opposite leg. Fig. 10, based on all the examinations, suggests that the reflex is more commonly present after 32 weeks' gestation than before, both in normal weight and small-for-dates babies. However, it is clear that the time of appearance of the reflex is far too unpredictable for it to provide an accurate assessment of gestational age.

Table VI gives the results of one observation per

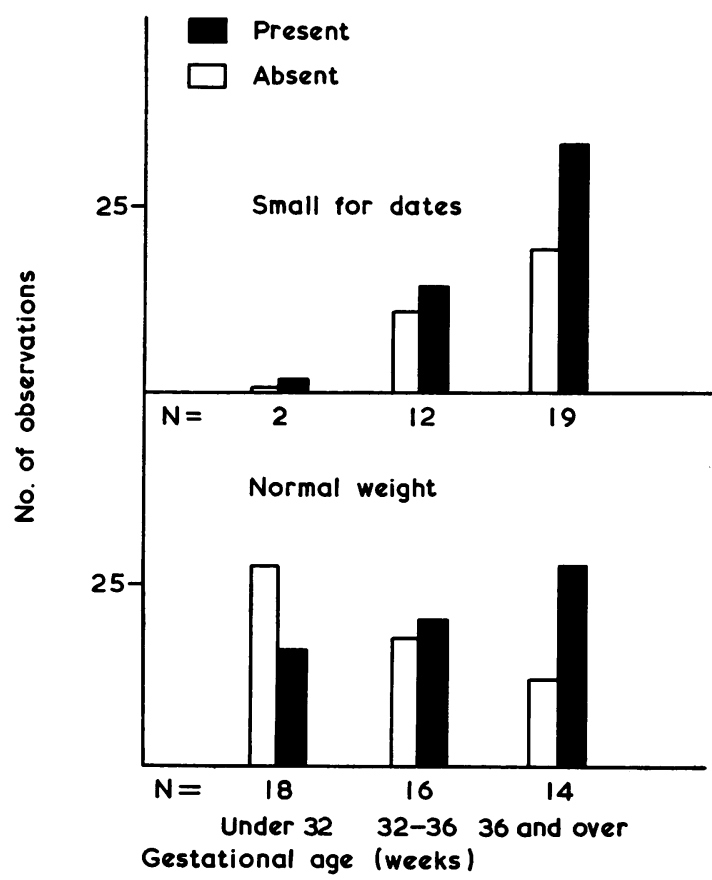

Fig. 10.-Crossed extensor reflex. Numbers of observations on small-for-dates and normal weight babies in each gestational period showing reflex present or absent. $N$ is the number of babies studied in the particular group and period.
TABLE VI

Crossed Extensor Reflex in First Week

\begin{tabular}{|c|c|c|c|c|}
\hline Group & Gestation & Present & Doubtful & Absent \\
\hline Normal weight & $\begin{array}{l}\text { Under } 32 \text { weeks } \\
32-36 \text { weeks } \\
36 \text { weeks and } \\
\text { over }\end{array}$ & $\begin{array}{l}7 \\
3 \\
2\end{array}$ & $\begin{array}{l}1 \\
2 \\
2\end{array}$ & $\begin{array}{r}11 \\
3 \\
4\end{array}$ \\
\hline Small-for-dates & $\begin{array}{l}\text { Under } 32 \text { weeks } \\
32-36 \text { weeks } \\
36 \text { weeks and } \\
\text { over }\end{array}$ & $\begin{array}{l}1 \\
5 \\
6\end{array}$ & $\begin{array}{l}0 \\
1 \\
1\end{array}$ & $\begin{array}{l}1 \\
4 \\
5\end{array}$ \\
\hline
\end{tabular}

$\chi^{2}$ (both groups combined $)=1 \cdot 73, p=0.7(\mathrm{~N}=4)$.

baby in the first week of life. The differences between the gestational periods are not significant $(p=0 \cdot 7)$. In the longitudinal studies on individual babies the reflex did not become positive at a particular gestational age and remain so, but varied to a large extent randomly in its presence or absence.

Adduction phase of Moro response, and knee-jerks. Both these responses behave in a very similar manner to the crossed extensor reflex. They are more constantly present after the period 32-36 weeks than before, but their times of appearance are too unpredictable and their presence or absence at any particular gestational age too random for them to be accurate measures of gestational age.

Cremasteric reflexes. Since these could only be tested on the male infants, the numbers were necessarily small. However, they are interesting because they show a pattern quite different from that of any of the other reflexes. Fig. 11 shows the results of all the observations in both groups. In the normal weight group the response generally appeared between 32 and 34 weeks and was constantly present after this. In the small-for-dates group however, the cremasteric reflexes were more frequently absent than present after 34 weeks. The fourfold table for a single observation on each baby of the normal weight group in the first week of life (Table VII) shows that the differences between the gestational periods are significant $(p<0.01)$ despite the small numbers.

The fourfold table comparing single observations in the first week on normal weight and small-fordates babies over 32 weeks' gestation (Table VIII) shows that the 2 groups behave significantly differently at the same gestational ages $(p<0.05)$.

Thus small-for-dates babies seem to behave in proportion to their body weight rather than to their gestational age in the case of this reflex. 


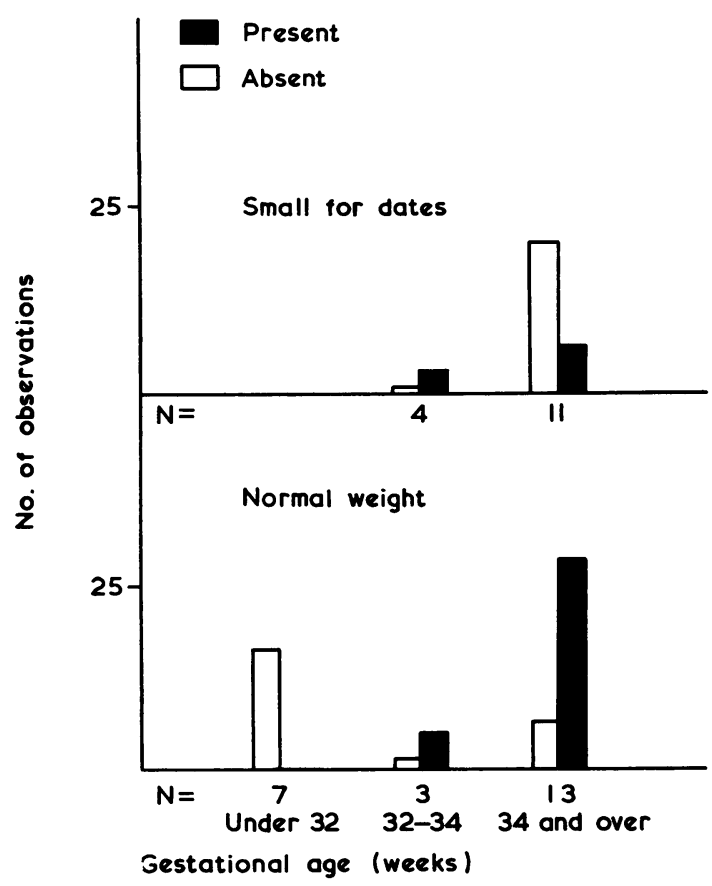

FIG. 11.-Cremasteric reflexes. Numbers of observations showing the reflexes present or absent on small-for-dates and normal weight babies in each gestational period. $N$ is the number of babies studied in the particular group and period.

TABLE VII

Cremasteric Reflexes in First Week (normal weight group)

\begin{tabular}{|c|c|c|c|}
\hline \multirow{2}{*}{\multicolumn{2}{|c|}{ Gestation }} & \multicolumn{2}{|c|}{$\begin{array}{l}\text { No. of Babies Showing } \\
\text { Cremasteric Reflexes }\end{array}$} \\
\hline & & Present & Absent \\
\hline $\begin{array}{l}\text { Under } 32 \text { weeks .. } \\
32 \text { weeks and over }\end{array}$ & $\begin{array}{l}\cdots \\
\cdots\end{array}$ & $\begin{array}{r}0 \\
11\end{array}$ & $\begin{array}{l}5 \\
2\end{array}$ \\
\hline
\end{tabular}

$\chi^{2}($ Yates' correction $)=7 \cdot 6, p<0.01$.

TABLE VIII

Cremasteric Reflexes in First Week (babies over 32 weeks' gestation)

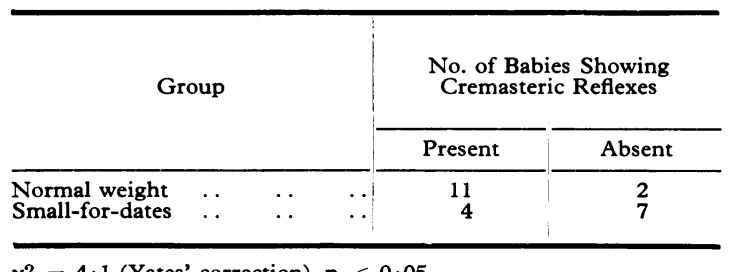

$\chi^{2}=4 \cdot 1$ (Yates' correction), $\mathrm{p}<0.05$.

\section{Discussion}

Previous studies. Neurological observations have been made on pre-viable foetuses by Minkowski (1924), Hooker (1952), and Humphrey (1964). The palmar grasp reflex and a response resembling the Galant are detectable at 9-11 weeks. The plantar grasp reflex and withdrawal on stimulation of the sole of the foot are present from 12 weeks. The abdominal reflexes are present from 14-20 weeks, and the Moro response has been reported at 25 weeks (Hooker, 1952). These correspond well with the group of responses which in the present study were constantly present even at 25 weeks' gestation. The blink response to light was also found constantly present from 25 weeks in the present study, but there is no published information about its presence or absence in more immature foetuses.

Premature infants have been studied neurologically by Gesell and Amatruda (1945), Saint-Anne Dargassies (1955), and Illingworth and Holt (1963). Gesell and Amatruda described changes such as the gradual increase in muscle tone and in the strength of the grasp and sucking reflexes in premature infants between 28 weeks' gestation and their expected term. Söderling (1953) and Bergström et al. (1955) have suggested that the maturational changes described by Gesell may be used to measure the true gestational age in small-for-dates babies. However, these authors do not give details of the criteria characteristic of different gestational ages. The most detailed study of neurological maturation in premature infants has been made by Madame Saint-Anne Dargassies of the Baudelocque Clinic, Paris, and much of the interest in this subject is due to her work. She has published observations on several very immature babies studied longitudinally and on 100 premature infants of varying gestational ages examined on one or more occasions (Saint-Anne Dargassies, 1955). She paid particular attention to spontaneous posture, muscle tone, and certain primitive reflexes and concluded that neurological maturation followed a constant time-scale which was unaffected either by the time of birth or by variations in body weight. Babies who have attained 40 weeks' gestation behave identically neurologically, whether or not they were born prematurely and whether they are of normal weight or underweight. There are, however, certain difficulties in extracting exact and easily applied criteria for the assessment of gestational age from Saint-Anne Dargassies' published observations. The gestational ages of her infants are not known with certainty, and the observations are not analysed in detail to show which of them change with gestational age, neither is the degree of constancy 
or statistical significance of the changes discussed. Furthermore, her assessment of maturity is based largely on changes in posture and muscle tone, and on the nature of the crossed extensor reflex. This reflex is discussed later; in the present study it was not found to be a reliable indicator of gestational age. Increasing muscle tone is certainly a prominent feature of advancing maturity, but since the increase is a gradual one, not a sudden change from absent to present as with some of the responses reported here, the measurement of gestational age from degree of muscle tone tends to be subjective and requires considerable experience. Saint-Anne Dargassies (1955), and Illingworth and Holt (1963) who base their methods largely on hers, have attempted to make their measurements more objective by describing certain postures of increasing flexion of the limbs, which are characteristic of certain gestational ages, and by measuring the 'extensibilité' of certain joints. This is the angle through which a joint can be extended, and it usually decreases with increasing gestational age, partly due to increased muscle tone and partly to other factors such as elasticity of ligaments. Certain values of the popliteal angle, for example, are said to be characteristic of certain gestational ages. However, some very immature babies in the present study had very limited extension at the knee joint, whereas some term babies permitted a very full range of movement. Prechtl (1965) has shown that limb posture after birth is to a large extent dependent on intrauterine position and mode of delivery.

There is no doubt that in very experienced hands gestational age can be fairly well assessed from the degree of muscle tone, and Illingworth and Holt (1963) claim an accuracy of 'within 2 weeks'. However, it is essential to have a method of assessment which is clear and practicable for any paediatrician concerned with newborn infants, and this is not fully provided by Illingworth and Holt's table of criteria of maturity (p. 252).

Of the 5 reflexes which in the present study showed a definite and predictable relation to gestational age, the only one about whose time of appearance there is any previous reliable information is the headraising part of the traction response, which corresponds to the 'redressement de tête' of Saint-Anne Dargassies. In many of her babies this appears to have been first detected at 7 or 8 (calendar) months' gestation-about 32-36 weeks-corresponding well with the present findings. Her only comment on the response of head-turning to diffuse light is that it was present in one prematurely born infant who had reached about 41 weeks' gestation. In the present study this response was found to be present at 32-36 weeks' gestation, at which period it was apparently not tested in Saint-Anne Dargassies' infants. She did not record the glabellar tap, neck-righting, or pupil responses, and commented that the latter were too difficult to observe for the reasons mentioned above. Such information as exists in the literature about pupil reactions is vague and confusing. Hess and Lundeen (1949) state that the pupils of premature babies react to light, but do not say at what gestational age. Magitot $(1921,1946)$ claims to have observed pupil reactions in foetuses in the 5 th month of gestation (i.e. less than 20 weeks) and Esente (1958) makes a similar statement. These authors do not give details of their observations which are totally at variance with the present findings, and it is difficult to see how they were made since the eyelids are normally fused at this gestational age (Duke-Elder, 1938).

Mechanism of maturation of reflexes. It must not be assumed that the absence of a particular reflex before a certain gestational age is necessarily due to functional immaturity of the reflex arc. The pupil reactions are always absent before 29 weeks' gestation, but the eye is clearly capable of detecting light and transmitting impulses to higher levels before this, as more immature babies show the blink response to light, and the electroencephalogram shows cortical potentials evoked by light at 28 weeks' gestation (J. P. M. Tizard and C. van Velzer, 1965, personal communication). The failure of the pupils to react to light may be related to the presence of the pupillary membrane (lamina irido-pupillaris) interfering with contraction of the iris. This mesodermal relic begins to disappear about 26-30 weeks' gestation (Keeney, 1951; Kronfeld, 1962). Likewise the absence of the cremasteric reflexes before 32 weeks' gestation may simply be due to poor scrotal development and incomplete testicular descent. This would explain why the presence or absence of this reflex in small-for-dates babies depends on their body weight rather than on their gestational age, in contrast to all the other reflexes studied.

The pathway of the reflex arc is not known in detail for most of the reflexes studied. It is generally believed that they are mediated by the brain-stem or spinal cord and do not involve the cerebral cortex, which is usually held to be nonfunctional in the term newborn baby (but see Robinson, 1966). The response of head-turning towards diffuse light, however, may be mediated by the occipital cortex (Goldie and Hopkins, 1964). If this is true, the present results suggest that the cortex is functioning in this respect at 32 weeks' gestation in some babies. 
TABLE IX Reflexes of Value in Assessing Gestational Age

\begin{tabular}{|c|c|c|c|c|}
\hline \multirow{2}{*}{ Reflex } & \multirow{2}{*}{ Stimulus } & \multirow{2}{*}{ Positive Response } & \multicolumn{2}{|c|}{ Gestation (wk.) if Reflex is } \\
\hline & & & Absent & Present \\
\hline $\begin{array}{l}\text { Pupil reaction } \\
\text { Traction } \\
\text { Glabellar tap } \\
\text { Neck-righting } \\
\text { Head-turning }\end{array}$ & $\begin{array}{l}\text { Light } \\
\text { Pull up by wrists from supine } \\
\text { Tap on glabella } \\
\text { Rotation of head } \\
\text { Diffuse light from one side }\end{array}$ & $\begin{array}{l}\text { Pupil contraction } \\
\text { Flexion of neck or arms } \\
\text { Blink } \\
\text { Trunk follows } \\
\text { Head-turning to light }\end{array}$ & $\begin{array}{l}<31 \\
<36 \\
<34 \\
<37 \\
\text { Doubtful }\end{array}$ & $\begin{array}{l}29 \text { or more } \\
33 \text { or more } \\
32 \text { or more } \\
34 \text { or more } \\
32 \text { or more }\end{array}$ \\
\hline
\end{tabular}

Note: '29 weeks' means 203 days after the first day of the last menstrual period. If there is a conflict between two results, the reflex placed higher in the Table is more likely to give the true gestational age.

Lack of influence of extrauterine factors on maturation. The gestational ages at which the reflexes could first be elicited were the same whatever the stage of gestation at which the baby was born. This was demonstrated by the longitudinal studies on babies born early in gestation, in whom the reflexes first became detectable at the same gestational age as that indicated by single observations in the first week of life on babies born at differing gestational ages. It was also demonstrated by the good correspondence between the results for any reflex of single examinations in the first week and those of the total series of examinations. The results therefore support Saint-Anne Dargassies' (1955) concept that neurological maturation in the latter third of gestation is neither accelerated nor retarded by extrauterine influences (other than obviously injurious ones). This does not necessarily apply to other aspects of neurological maturation which were not tested (Robinson and Tizard, 1966). It would be surprising if visual development in premature infants were not influenced by degrees and variations of illumination which the foetus in utero cannot experience. However, the visual responses tested showed no evidence of such an influence.

Lack of influence of intrauterine growth retardation. The gestational age at which each reflex first appeared was uninfluenced by birthweight, being the same in small-for-dates babies as in those having a normal birthweight for their gestational age (except the cremasteric reflexes-see above). This is of great practical importance because the usefulness of a neurological assessment of gestational age is to decide whether a particular baby of low birthweight is a true premature or smallfor-dates. A statistically significant difference in behaviour was demonstrated between babies of similar birthweight but different gestational ages, for the pupil reactions and the glabellar tap and traction reflexes. The lack of influence of intrauterine growth retardation on neurological maturation, which was also reported by Saint-Anne Dargassies
(1955) and by Illingworth and Holt (1963), is of theoretical interest too. It corresponds with the relatively large size and advanced development of the brain in small-for-dates babies, which indicate that this organ is largely spared from the effects of intrauterine undernutrition (Gruenwald, 1963; Dawkins, 1965).

Assessment of gestational age. To be a useful indicator of gestational age, a reflex must have a relatively clear-cut time of appearance which is constant from baby to baby, and which is the same in small-for-dates babies as in those of normal birthweight. Five reflexes fulfilled these criteria. In order of reliability assessed statistically they were the pupil reactions to light (appearing at 29-31 weeks' gestation), traction response (33-36 weeks), glabellar tap reflex (32-34 weeks), neck-righting reflex (34-37 weeks), and head-turning to light (32-36 weeks). It is suggested that gestational age should be measured as lying between or beyond stated limits on the basis of presence or absence of these responses (see Table IX).

At the lower and upper ends of the gestational scale it is strictly only possible on the basis of the table to say a baby is less than 31 or more than 34 weeks' gestation. In practice this is sufficient to resolve most clinical problems, since the important doubts concerning a baby's gestational age usually concern differences of 4 weeks (the menstrual cycle) or more. However, the range can be extended a little further if required, since babies with absent pupil responses (or fused eyelids) are usually less than 30 weeks'gestation, and those who have vigorous traction responses involving the neck and arms or brisk head-turning to light are likely to exceed $35-36$ weeks.

Although other reflexes showed some relation to gestational age, they were found to be too inconstant in their behaviour to serve as indices of maturity. They have not been included in this Table since they would not extend its range, and if their results conflicted with those of the more reliable reflexes they would be ignored. Saint-Anne Dargassies 


\section{Assessment of Gestational Age by Neurological Examination}

(1955) and Illingworth and Holt (1963) attach considerable importance to the crossed extensor reflex, which in the present study proved an unreliable index of maturity. These authors describe three phases in the development of the reflex, of which only one (extension) was studied here. However, this cannot fully explain the difference in findings, since in the present study the extension phase did not correlate with maturity as well as they have suggested.

In general the method of assessing gestation just described differs from that of Saint-Anne Dargassies because it uses discontinuous variables which change from negative to positive during a relatively short period, rather than continuous variables such as muscle tone, posture, and strength of responses, which increase or change steadily during the whole of the last third of gestation. It is hoped that it will, therefore, prove easier to apply. It is also felt that the limits of confidence in the assessment are more clearly stated in the present study.

\section{Summary}

A number of reflexes has been studied in 219 standard neurological examinations carried out on 62 infants born at known gestational ages between 25 and 42 weeks. 37 of the infants were of normal birthweight for their gestational age, and 25 were small-for-dates (defined as more than $25 \%$ below the mean birthweight for their gestational age).

The palmar and plantar grasp, the abduction phase of the Moro reflex, and the withdrawal reflex on stimulation of the sole of the foot were constantly present, and the Galant reflex and blink response to light were almost constantly present, whatever the baby's gestational age.

Another group of reflexes was absent in the most immature babies, appearing at predictable times in the latter third of the gestational period. The pupil reactions to light were present from 29-31 weeks' gestation, the glabellar tap reflex from 32-34 weeks, the traction response from 33-36 weeks, the neckrighting reflex from 34-37 weeks, and the response of head-turning to diffuse light from 32-36 weeks. The gestational age after which one of these reflexes is detectable is the same whether the baby has been maturing inside or outside the uterus. The gestational age at which a reflex appeared was also the same in small-for-dates babies as in those having a normal birthweight for their gestational age. The presence or absence of these reflexes can therefore be used to assess the gestational age of a baby of low birthweight and to determine whether it is small-fordates or truly premature.

The presence of certain other reflexes, such as the crossed extensor reflex and the adduction phase of the Moro reflex, also depended on gestational age, but the relationship was too inconstant for them to be reliable indices of gestational age.

The method is compared with other work on neurological maturation in premature infants, and the theoretical and practical interest of the results is discussed.

I am grateful to Professor J. P. M. Tizard and Dr. J. A. Davis for allowing me to examine the babies under their care and for helpful discussions, to Dr. Heinz Prechtl for his interest and for a helpful discussion of results, and to the Sir William Coxen Trust for provision of facilities.

\section{REFERENCES}

Bergström, A. L., Gunther, M. B., Olow, I., and Söderling, B. (1955). Prematurity and pseudoprematurity. Studies of the developmental age in underweight newborns. Acta paediat. (Uppsala), 44, 519.

Butler, N. R., and Bonham, D. G. (1963). Perinatal Mortality. Livingstone, Edinburgh.

Dawkins, M. (1965). The biology of prematurity. Develop. Med. Child Neurol., 7, 74.

Duke-Elder, W. S. (1938). Textbook of Ophthalmology, Vol. I, p. 364. Kimpton, London.

Esente, I. (1958). Physiologie de la Vision chez le Prématuré et le Nourrisson Normal, p. 69. Doin, Paris.

Gesell, A., and Amatruda, C. S. (1945). The Embryology of Behavior. Harper, New York and London.

Goldie, L., and Hopkins, I. J. (1964). Head turning towards diffuse light in the neurological examination of newborn infants. Brain, 87, 665 .

Gruenwald, P. (1963). Chronic fetal distress and placental insufficiency. Biol. Neonat. (Basel), 5, 215.

Hess, J. H., and Lundeen, E. C. (1949). The Premature Infant, 2nd ed., p. 16. Lippincott, Philadelphia.

Hooker, D. (1952). The Prenatal Origin of Behavior. University of Kansas Press, Lawrence, Kansas.

Humphrey, T. (1964). Some correlations between the appearance of human fetal reflexes and the development of the nervous system. Progr. Brain Res., 4, 93.

Illingworth, R. S., and Holt, K. S. (1963). The determination of maturity. In The Development of the Infant and Young Child: Normal and Abnormal, by R. S. Illingworth, 2nd ed., pp. 251253. Livingstone, Edinburgh.

Keeney, A. H. (1951). Chronology of Ophthalmic Development: An Outline Summary of the Anatomical and Functional Development of the Visual Mechanism Before and After Birth. Charles C. Thomas, Springfield, Illinois.

Kronfeld, P. C. (1962). The gross anatomy and embryology of the eye. In The Eye, ed. H. Davson, Vol. 1, pp. 1-62. Academic Press, New York.

Magitot, A. (1921). L'Iris, p. 189. Doin, Paris.

- (1946). Physiologie Oculaire Clinique. Masson, Paris.

Minkowski, M. (1924). Zum gegenwărtigen Stand der Lehre von den Reflexen in entwicklungsgeschichtlicher und anatomischphysiologischer Beziehung. Schweiz. Arch. Neurol. Psychiat., 15, 239.

Prechtl, H. F. R. (1965). Problems of behavioral studies in the newborn infant. Advanc. Study Behav., 1, 75.

- and Beintema, D. (1964). The neurological examination of the full-term newborn infant. Little Club Clin. develop. Med., 12.

Robinson, R. J. (1966). Cerebral function in the newborn. Develop. Med. Child Neurol. In the press.

, and Tizard, J. P. M. (1966). The central nervous system in the new-born. Brit. med. Bull., 22, 49.

Saint-Anne Dargassies, S. (1955). La maturation neurologique du prématuré. Étud. néo-natal., 4, 71.

Scott, K. E., and Usher, R. (1964). Epiphyseal development in fetal malnutrition syndrome. New Engl. f. Med., 270, 822.

Söderling, B. (1953). Pseudoprematurity. Acta paediat. (Uppsala), 42, 520.

Wigglesworth, J. S. (1966). Foetal growth retardation. Brit. med. Bull., 22, 13. 